\title{
On optical and microphysical characteristics of contrails and cirrus
}

\author{
Guy Febvre, ${ }^{1,2}$ Jean-François Gayet, ${ }^{1}$ Andreas Minikin, ${ }^{3}$ Hans Schlager, ${ }^{3}$ \\ Valéry Shcherbakov, ${ }^{1}$ Olivier Jourdan, ${ }^{1}$ Reinhold Busen, ${ }^{3}$ Markus Fiebig, ${ }^{4}$ \\ Bernd Kärcher, ${ }^{3}$ and Ulrich Schumann ${ }^{3}$
}

Received 27 March 2008; revised 18 September 2008; accepted 21 November 2008; published 24 January 2009.

[1] In situ measurements of light scattering and microphysical characteristics of young and 20-min-aged persistent contrails and of frontal cirrus clouds were carried out with the airborne polar nephelometer and microphysical Particle Measuring Systems instruments. Optical and microphysical properties of contrails at different stages of evolution and of cirrus clouds sampled in ice-supersaturated air masses at ambient temperatures near $-60^{\circ} \mathrm{C}$ are examined. The results show that quasi-spherical ice particles with diameters smaller than $5 \mu \mathrm{m}$ control the optical properties of the plume shortly after formation. In slightly aged contrails the optical properties are governed by larger nonspherical ice crystals. Very similar optical properties are observed in frontal cirrus but with a different ice particle size distribution. The contrail optical and microphysical ice particle data obtained in this study are representative of the visible persistent contrail created by a midsized airliner after the wake vortices have decayed.

Citation: Febvre, G., J.-F. Gayet, A. Minikin, H. Schlager, V. Shcherbakov, O. Jourdan, R. Busen, M. Fiebig, B. Kärcher, and U. Schumann (2009), On optical and microphysical characteristics of contrails and cirrus, J. Geophys. Res., 114, D02204, doi:10.1029/2008JD010184.

\section{Introduction}

[2] Condensation trails (contrails) are aircraft induced clouds and may be viewed as artificial cirrus. To a large extent, contrails may persist and grow like natural cirrus in supersaturated air, and may cause anthropogenic warming of the atmosphere. Over the last 10 years several intensive studies from both experiments and modeling exercises have been carried out in this field. The main results and findings were described in a recent review by Schumann [2005]. Although the key processes involved in contrail formation are well understood, the optical properties of these clouds as a function of time after formation are still poorly characterized [Schröder et al., 2000a]. For quantification of radiative forcing one needs to know differences between contrails and natural cirrus clouds with respect to ice particle number, sizes, shapes and their changes with age. The importance of aviation induced clouds is emphasized by observed increases of cirrus occurrence which was evidenced, e.g., by Stubenrauch and Schumann [2005] in regions where air traffic is very high and where the air is cold and humid enough to let contrails form. So far, only a few in situ observations are available concerning the microphysical properties of young contrails,

\footnotetext{
${ }^{1}$ Laboratoire de Météorologie Physique, UMR6016, Université Blaise Pascal, CNRS, Aubière, France.

${ }^{2}$ Antenne d'Aurillac, Institut Universitaire de Technologie de ClermontFerrand, Université d'Auvergne, Clermont-Ferrand, France.

${ }^{3}$ Institut für Physik der Atmosphäre, Deutsches Zentrum für Luft- und Raumfahrt, Wessling, Germany.

${ }^{4}$ Norwegian Institute for Air Research, Kjeller, Norway.

Copyright 2009 by the American Geophysical Union. 0148-0227/09/2008JD010184
}

stemming from three major experiments, i.e., the SULFUR experiments carried out over Germany [Petzold et al., 1997; Schumann et al., 2002], the SUCCESS project carried out over the U.S. [Baumgardner and Gandrud, 1998; Goodman et al., 1998; Lawson et al., 1998; Heymsfield et al., 1998] and the European AEROCONTRAIL project held over Germany [Ström and Ohlsson, 1998; Gayet et al., 1998; Schröder et al., 2000a]. Inside the contrail core it is generally observed that the ice particles remain small $(1-10 \mu \mathrm{m})$ because of high number concentrations $\left(10^{1}\right.$ to $\left.10^{2} \mathrm{~cm}^{-3}\right)$ whereas along the contrail periphery the crystal may grow to several hundred microns if favorable dynamical (sufficiently supersaturated) conditions occur [Lawson et al., 1998]. Particle growth increases with ambient temperature. Lidar pictures show that contrails sometimes lead to large and sedimenting ice particles [Schumann, 1994; Freudenthaler et al., 1995; Atlas et al., 2006].

[3] This paper presents the results of a case study of in situ microphysical and optical measurements performed in a young (about $2.5 \mathrm{~min}$ age) and a slightly aged (less than $20 \mathrm{~min}$ ) persistent contrail as well as in "natural" (i.e., without signals of fresh aircraft emissions) cirrus clouds in a similar environment. The observations were carried out over Germany in September 2005 during the German PAZI-2 (PArtikel und ZIrren, i.e., Particles and Cirrus Clouds) project with the German DLR (Deutsches Zentrum für Luft- und Raumfahrt) Falcon aircraft operated from Oberpfaffenhofen near Munich. The general PAZI-2 scientific objectives are to better understand the formation of the ice phase in cirrus clouds from natural and anthropogenic aerosols and to improve microphysical and optical parameterizations of cirrus clouds in global models. The measurements reported here were performed as 
part of the PAZI-2 project during the international 'Lindenberg Campaign for Assessment of Humidity and Cloud Profiling Systems' (LAUNCH) organized by DWD (German weather service).

\section{Instrument Description and Measurements}

\subsection{Cloud Measurements}

[4] Three instruments were used to assess the microphysical and optical properties of contrails and cirrus clouds: (1) the Particle Measuring Systems (PMS) FSSP-300 operated by DLR, (2) the PMS 2D-C and (3) the polar nephelometer probes, both operated by LaMP. Thanks to the combination of these three independent techniques, a description of particles within a range of diameters varying from a few micrometers (typically $1 \mu \mathrm{m}$ ) to $800 \mu \mathrm{m}$ was possible.

[5] The PMS FSSP-300 optical particle counter nominally measures particles from 0.3 to $20 \mu \mathrm{m}$ in diameter [Baumgardner et al., 1992]. Laboratory size calibrations were performed during the experiment. After this, following the recommendations by Baumgardner et al. [1989] some channels were grouped together in order to minimize the Mie ambiguities related to the probe diameter response. As a result, nine channels were rebinned from the 23 original channels (the first eight channels were not used) giving a size range of diameter from 1.0 to $28.4 \mu \mathrm{m}$ assuming spherical ice particles. Coincidence effects on particle sizing have not been taken into account in data processing because it is hypothesized that these effects do not significantly affect the ice crystal size spectra [Baumgardner et al., 1992].

[6] The PMS 2D-C probe provides information on crystal size and shape for the size range $25-800 \mu \mathrm{m}$. The method of data processing used in this study has already been described in detail by Gayet et al. [2006]. The "reconstructed" method, which considers partial images, has been considered here for the calculations and the sampling surfaces have been derived accordingly [Heymsfield and Parrish, 1978]. In order to improve the statistical significance of low particle concentrations, a $5 \mathrm{~s}$ running mean was applied. Irregular ice particles were the most predominant crystals sampled during the PAZI-2/LAUNCH experiment. Therefore, the bulk parameters were calculated assuming the surface-equivalent diameter relationships given by Heymsfield [1972] and Locatelli and Hobbs [1974]. As the sensitivity of the probe to small particles decreases with airspeed (i.e., $\sim 200 \mathrm{~m} \mathrm{~s}^{-1}$ with the Falcon aircraft), the first six channels (up to $150 \mu \mathrm{m}$ ) were corrected according to the results of Baumgardner and Korolev [1997]. Recent studies (P. Lawson, personal communication, 2008) suggest that these corrections may not fully take into account the response time of the $2 \mathrm{D}-\mathrm{C}$ probe particularly when used at about $200 \mathrm{~m} \mathrm{~s}^{-1}$. At these velocities particles smaller than about $150 \mu \mathrm{m}$ may not be detectable. After correction, some of the small particles may in fact be larger particles that are being undersized because of the slow response time and/or the limits of the depth of field. This results in large uncertainties in derived parameters, particularly concerning IWC derivation, as discussed below. In order to allow for comparisons with previous results such as midlatitude cirrus properties during INCA, the $2 \mathrm{D}-\mathrm{C}$ data have been processed with the same assumptions and techniques described by Gayet et al. [2006].
[7] In the following, the microphysical parameters were obtained by summing the contributions of the PMS FSSP300 and $2 \mathrm{D}-\mathrm{C}$. The parameter definitions are as follows: (1) Ice particle concentration (Conc), (2) Extinction coefficient (Ext), (3) Ice water content (IWC) and (4) Effective diameter $\left(D_{e f f}\right)$. The accuracy of derived microphysical parameters is considerably affected by inherent shortcomings of probes and parameterizations. Assuming a sampling time of $5 \mathrm{~s}$, the total random uncertainties were estimated as ranging from $75 \%$ to $100 \%$ for PMS probe data (see details in the work by Gayet et al. [2002a]). In addition, systematic errors occur (including ice crystal-shattering effects, see section 2.2), in particular when ice particles with diameter larger than about $100 \mu \mathrm{m}$ are present (see section 2.2).

[8] The polar nephelometer [Gayet et al., 1997] measures the scattering phase function of an ensemble of cloud particles (i.e., water droplets or ice crystals or a mixture of these particles ranging from a few micrometers to about $800 \mu \mathrm{m}$ diameter), which intersect a collimated laser beam near the focal point of a parabolic mirror. The light source is a highpower $(1.0 \mathrm{~W})$ multimode laser diode operating at $\lambda=804 \mathrm{~nm}$. The data acquisition system of the polar nephelometer is designed to provide a continuous sampling volume by integrating the measured signals of each of the detectors over a selected period. For instance, the sampling volume $(v)$ is determined by the sampling surface $(10 \mathrm{~mm}$ long and $5 \mathrm{~mm}$ diameter beam) multiplied by the Falcon cruise speed of approximately $200 \mathrm{~m} \mathrm{~s}^{-1}$, i.e., $1 \mathrm{~L}$ for an acquisition frequency of $10 \mathrm{~Hz}$. This means that the detection threshold is close to one particle per liter at this frequency. Direct measurement of the scattering phase function allows particle types (water droplets or ice crystals) to be distinguished and calculation of the optical parameters to be performed (extinction coefficient and asymmetry parameter [see Gayet et al., 2002b]). Nonabsorbing ice particles randomly oriented in the sampling section are assumed in deriving bulk quantities. The accuracies on the extinction coefficient and asymmetry parameter determination are estimated to be within about $25 \%$ and $4 \%$ respectively [Gayet et al., 2002b]. These accuracies could be considerably affected by ice crystal shattering on the probe inlet.

\subsection{Effects of Ice Crystal Shattering on Measurements}

[9] It has been questioned whether high ice crystal concentrations often observed with the FSSP instrument, particularly under conditions with large ice crystals, are real, or an artifact caused by shattering of large ice crystals on protruding probe inlets [Korolev and Isaac, 2005]. Heymsfield [2007] modeled the probe responses to different combinations of IWC and large particle concentration. In relatively extreme situations, the results show that the shattering effects could add about $15 \%$ to the IWC from the FSSP, while the problem is even greater for extinction and number concentration. McFarquhar et al. [2007] experimentally confirm that shrouded inlets may cause particle shattering with a subsequent enhancement of the total concentration of ice crystals especially at $\mathrm{D}<50 \mu \mathrm{m}$. For particle diameters larger than about $100 \mu \mathrm{m}$, the number of shattered particles increases with the concentration of large particles. Techniques have been proposed by Field et al. [2003, 2006] to separate real and artifact-shattered crystals from information of ice particle interarrival times (from either fast FSSP or 


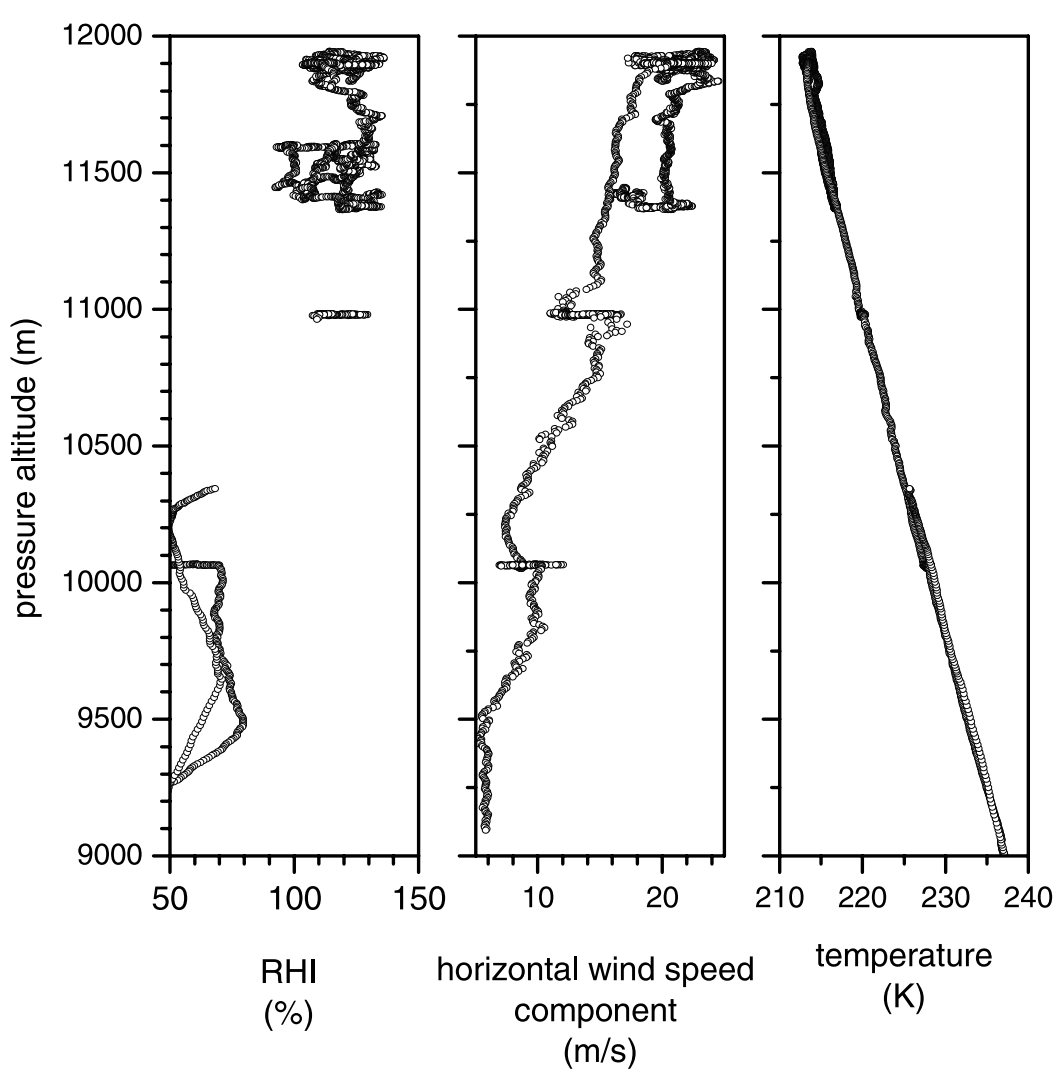

Figure 1. Measured relative humidity (with respect to ice), horizontal wind speed component perpendicular to the flight path, and temperature versus altitude.

2D-C probes) making objective corrections possible. New particle image probes (including the $2 \mathrm{D}-\mathrm{S}$ instrument) with high-pixel resolution may also be used to quantify the contribution of shattering to the particle size distributions and optical properties measured by probes with shrouded inlet (FSSP and polar nephelometer for instance) (Lawson, personal communication, 2008), however, these instruments were not available for the present study. The possible effects of ice crystal shattering on the present study will be discussed together with the results (section 3.3.1).

\subsection{Other Measurements}

[10] Water vapor measurements have been obtained with a CR-2 frost point hygrometer [Busen and Buck, 1995] which has shown its ability to provide reliable measurements in high-humidity conditions at low temperature.

[11] Measurements of the number concentrations of aerosol particles were made with six Condensation Particle Counters (CPC) modified for aircraft operation at low ambient pressure [Petzold et al., 2007]. Total number concentrations of condensation nuclei $(\mathrm{CN})$ were determined with a CPC with the lowest detectable particle size set to $10 \mathrm{~nm}$. Similarly, the nonvolatile particle concentration was measured by a CPC operating behind a thermodenuder heated to $250^{\circ} \mathrm{C}$.

[12] The NO and NOy measurements were performed using a $\mathrm{NO} / \mathrm{O}_{3}$ chemiluminescence technique [Schlager et al., 1997]. Sample air was passed through a single PFA tube from outside the aircraft boundary layer via a backward facing inlet. Inside the cabin the sample air was split into the
$\mathrm{NO}$ and NOy channels. In the NOy channel the air was first passed through a heated gold converter [Ziereis et al., 2000] where the different NOy compounds are reduced to NO. In young aircraft plumes NOy is mainly composed of $\mathrm{NO}$ and $\mathrm{NO}_{2}$. The accuracy/precision of the $\mathrm{NO}$ and NOy measurements is $7 / 10 \%$ and $10 / 15 \%$, respectively. Ozone and CO were measured with UV absorption [Schlager et al., 1997] and vacuum UV fluorescence technique [Gerbig et al., 1996]. All chemical data were recorded with 1s resolution.

\section{Observations}

[13] The observations were obtained during an anticyclonic situation on 14 September 2005, in an area located in east Germany between 0630 and 0730 UT. Figure 1 displays the vertical profiles of the temperature and the relative humidity (RHi, with respect to ice) obtained from the aircraft measurements during the flight ascent. At the highest flight pressure altitudes, no noticeable decrease in the temperature lapse rate was observed. Consistently, ozone measurements showed that, except for a 4 min section with ozone mixing ratios slightly increasing to $100 \mathrm{nmol} \mathrm{mol}^{-1}$, the entire flight was located inside the troposphere with ozone mixing ratios below $75 \mathrm{nmol} \mathrm{mol}^{-1}$. The RHi profile shows rather dry air in the troposphere with a sharp gradient near $11,200 \mathrm{~m}$ $\left(-56^{\circ} \mathrm{C}\right)$ and a supersaturated (RHi up to $130 \%$ ) layer above (even inside cloud parts) with a mean wind of $27 \mathrm{~m} \mathrm{~s}^{-1}$ from the northwest $\left(320^{\circ}\right)$ direction. Broken frontal cirrus clouds with low optical depth (relatively transparent from aircraft observations) were observed in this layer and the humidity 


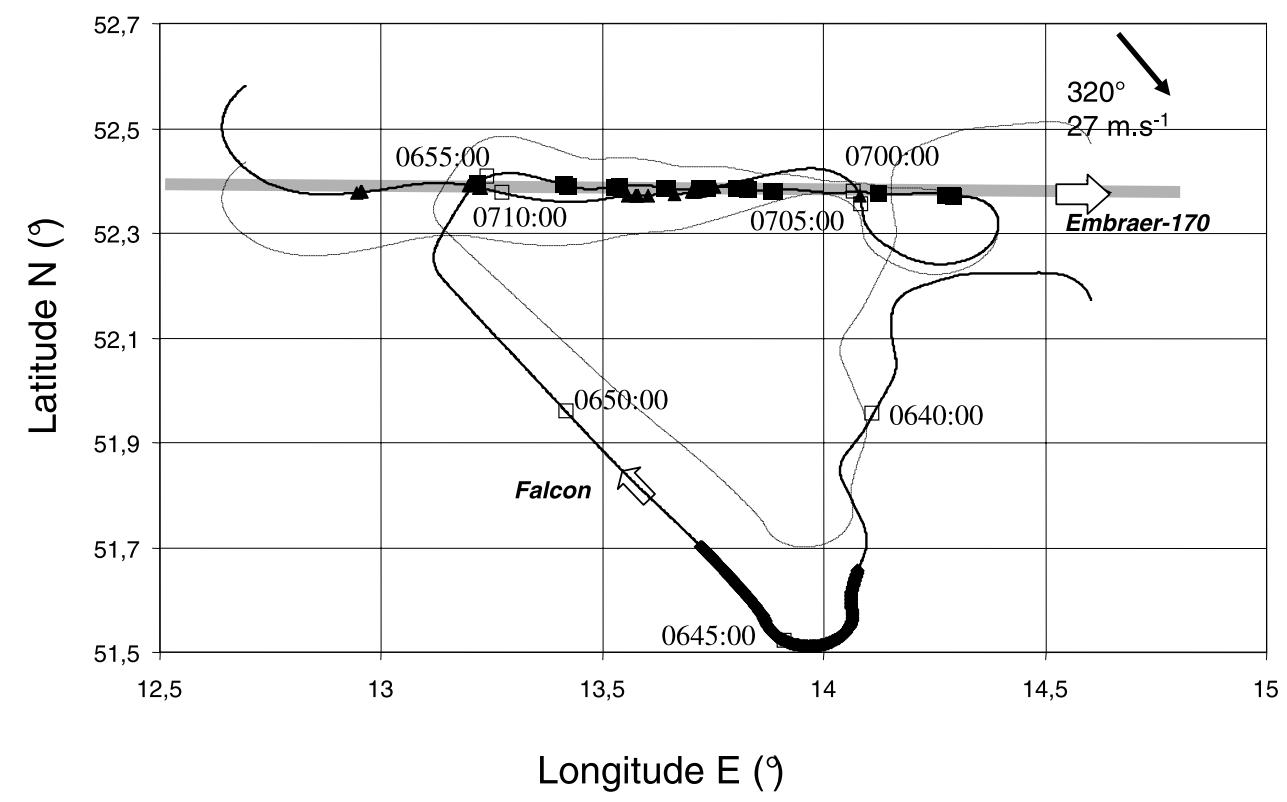

Figure 2. Trajectories of the Embraer-170 and Falcon aircraft (thin line) plotted in a Lagrangian reference related to the mean horizontal wind $\left(27 \mathrm{~m} \mathrm{~s}^{-1}, 320^{\circ}\right)$. The origin of the Lagrangian reference was taken equal to the geographic reference frame at 0701:41 (UT). The thick line represents the cirrus cloud sequence. Solid squares and triangles denote the samplings of the young and aged contrail, respectively. The finer line is the trajectory of the Falcon aircraft in geographic reference frame.

was high enough to allow for the formation of persistent contrails. The flight strategy was to sample contrails within a specifically designated box area of $100 \mathrm{~km} \times 80 \mathrm{~km}$ dimension set up over Lindenberg (east of Berlin) in collaboration with the Upper Airspace Air Traffic Control (ATC) of Karlsruhe, Germany. Despite a complex cloudy situation with contrails partly embedded into remnant patches of cirrus, the Falcon pilots managed to track into contrails of commercial aircraft using visual navigation with the guidance of the air traffic controllers aided by the presence of a science team member. The real-time indication of several measurements performed onboard the aircraft $(\mathrm{NO} / \mathrm{NOy}$ and $\mathrm{CN}$ data, as well as FSSP-300 and polar nephelometer counts) were used to confirm the contrail penetrations and therefore gave additional information to refine the flight pattern. The Falcon did not aim at flying inside the contrail as long as possible, but rather at meandering repeatedly in and out of the visible contrail, in order to assess the contrail dimension, to reevaluate the flight pattern on the basis of visual assessment from outside of the contrail and to avoid the mixing of the target contrail with the Falcon's own contrail.

[14] In the following, we focus on a section of the flight with successive samplings at similar thermodynamic conditions of frontal cirrus and a particular contrail at different stages of evolution. The contrail was created by a midsized Polish Airlines (LOT) passenger twin-engine aircraft, an Embraer-170 jet, flying at $220 \mathrm{~m} \mathrm{~s}^{-1}$ at flight level 390 $(39,000 \mathrm{ft}, 11,900 \mathrm{~m}, 196 \mathrm{hPa})$. The Falcon followed at a little smaller speed of about $200 \mathrm{~m} \mathrm{~s}^{-1}$. Figure 2 represents the Falcon flight track plotted in a Lagrangian reference by considering an air advection of $27 \mathrm{~m} \mathrm{~s}^{-1}$ from $320^{\circ}$. The Falcon first sampled a cirrus cloud between 0643:00 and 0646:30 UT at 11,400 $\mathrm{m}$ altitude (marked with a thick line in
Figure 2). Then, with the help of ATC, the Falcon was guided behind the Embraer-170 aircraft. The Falcon climbed to approx. $11,900 \mathrm{~m}\left(-60^{\circ} \mathrm{C}\right)$ in order to follow the clearly visible young contrail for about $7 \mathrm{~min}$ (from 0655 to $0702 \mathrm{UT}$, see solid squares in Figure 2) during which several penetrations of the contrail were achieved within an altitude range of about 11,860-11,920 m. Taking into account the wind advection, a time lag of $2.5 \mathrm{~min}$ was found to give the best possible overlap of the flight paths of the Embraer-170 (provided by ATC from radar observations) and the Falcon at the time of the contrail measurements (see Figure 2). This means that the young contrail was sampled repeatedly by the Falcon approximately $2.5 \mathrm{~min}$ after the emission. At $0702 \mathrm{UT}$ the Falcon performed a U-turn to fly again into the aging Embraer-170 contrail (see triangles in Figure 2), which was visually spreading and getting optically thinner but was still distinguishable from the cockpit against background. The aging contrail was found at about the same altitude $(11,900 \mathrm{~m}$, FL390) as before. Between 0707 and 0712 UT the contrail was penetrated four more times between 11,885 and 11,915 m altitude, corresponding to a contrail age ranging between $11 \mathrm{~min}$ and $20 \mathrm{~min}$, again inferred from the relative positions of the aircraft taking into account the wind vector measured by the Falcon at flight level. After that the Falcon entered an apparently natural cirrus cloud and the aging contrail was visually lost.

[15] Infrared images of the MSG satellite (Meteosat Second Generation; images not presented here) clearly show that a cirrus band associated with a warm front was moving over Lindenberg during the Falcon flight period. A rough estimate of the advection gives $25 \mathrm{~m} \mathrm{~s}^{-1}$ from the northwest direction, a value close to the wind speed measured in the cloud layer. The cirrus layer was observed between about $9500 \mathrm{~m}$ and $12,000 \mathrm{~m}$ during a vertical sounding performed by the Falcon 


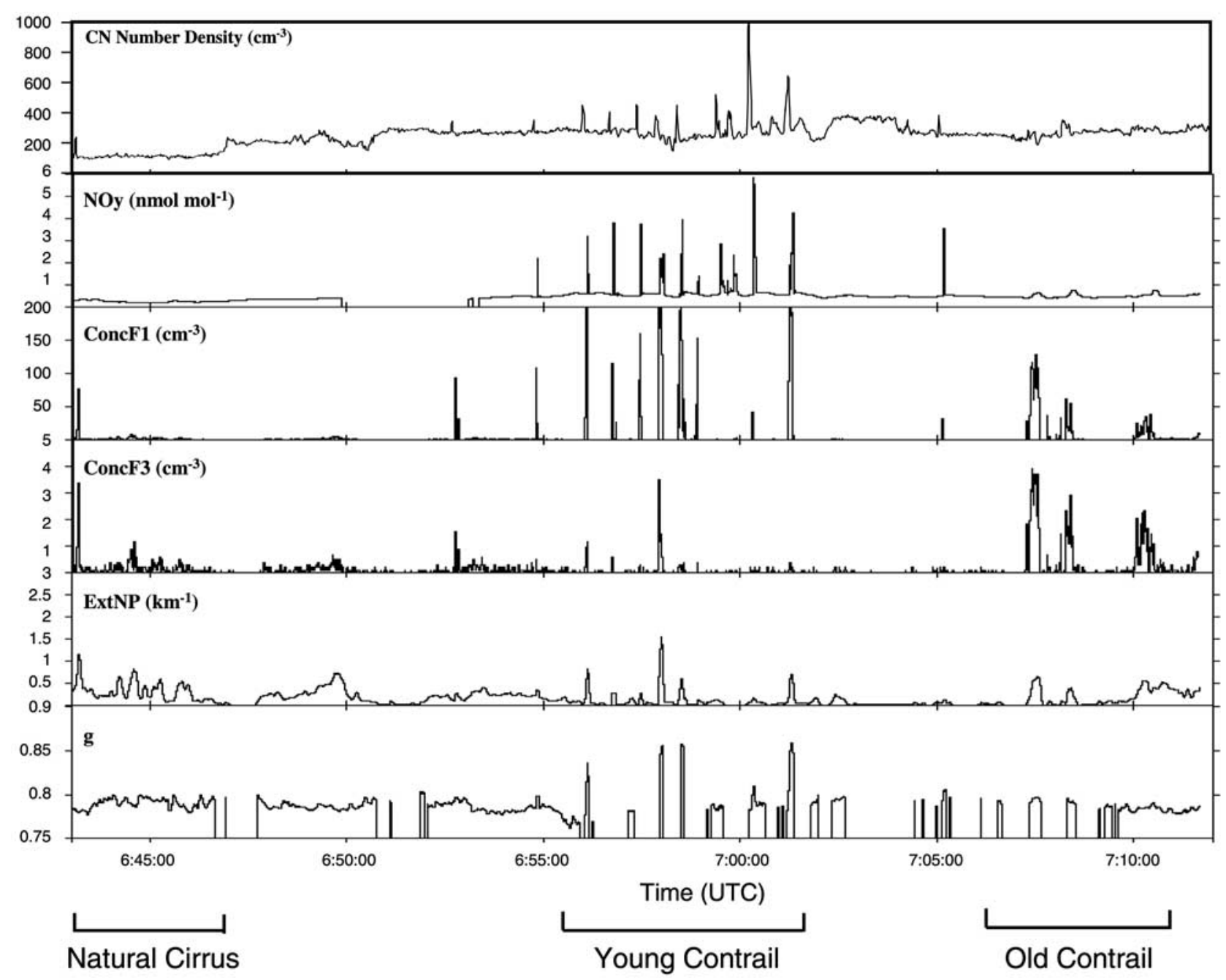

Figure 3. Time series of the parameters measured by the Falcon aircraft at $12,300 \mathrm{~m}\left(-60^{\circ} \mathrm{C}\right)$ between 0643 and 0712 UT on 14 September 2005. CN, number concentration of condensation nuclei; NOy, NOy gas trace; ConcF1 and ConcF3, concentration of particles with diameters larger than $1 \mu \mathrm{m}$ and $3 \mu \mathrm{m}$, respectively; ExtNP, extinction coefficient; $g$, asymmetry parameter.

after the contrail study in the vicinity of Lindenberg. Therefore during the period discussed in this paper (i.e., between 0640 and 0710) the Falcon performed measurements inside the frontal cirrus cloud.

[16] In the same satellite images a number of persistent contrails were discernable in the region at the time of investigation, but the particular contrail investigated in this study could not be identified with certitude because of low contrast of the contrail signature relative to the low infrared radiation from the partly cloudy atmosphere below the contrail.

\subsection{Overview on Measurements During Contrail Interceptions}

[17] The cloud sequences and the contrail penetrations along the Falcon flight track are depicted in Figure 3. Figure 3 displays time series of $\mathrm{NOy}$ and $\mathrm{CN}$ measurements along with the microphysical and optical parameters such as the concentration of particles with diameter greater than $1 \mu \mathrm{m}$ (ConcF1) and greater than $3 \mu \mathrm{m}$ (ConcF3), both derived from the FSSP-300 data, the extinction coefficient (ExtNP) and the asymmetry parameter $(g)$, derived from the polar nephelometer data.

[18] Relative humidity with respect to ice varied in the flight section of Figure 3 between 108 and 131\% (Figure 1), the temperature at $11,900 \mathrm{~m}$ altitude (FL390) was $-60^{\circ} \mathrm{C}$. The Schmidt-Appleman criterion for contrail formation is well fulfilled (the ambient temperature is below the threshold temperature of $-51.4^{\circ} \mathrm{C}$ for ice saturation at the given ambient conditions and the propulsion efficiency greater than 0.3 [Schumann, 2000]). The high measured ice supersaturation is consistent with the visual observation which indicate that the contrail is persistent. Contrails would form also $500 \mathrm{~m}$ below the observed contrail according to the measurements $\left(-51^{\circ} \mathrm{C}\right.$, RHi in the range $\left.108-135 \%\right)$.

[19] The penetrations of the young contrail (roughly 2.5 min age) are clearly indicated in Figure 3 by the relatively sharp peaks in the aircraft engine exhaust tracers, NOy and $\mathrm{CN}$, as well as in well correlated events in the ice particle measurements. Peaks in the number concentration of the small ice particles larger $1 \mu \mathrm{m}(\mathrm{ConcF} 1)$ reach up to $200 \mathrm{~cm}^{-3}$ and are accompanied by values of the asymmetry parameter of 
larger than 0.8 . The concentration of particles larger than $3 \mu \mathrm{m}$ (ConcF3) remains very low (a few per $\mathrm{cm}^{3}$ ) with an exception at 0657:50 UT. The peaks in NOy, which are superimposed on the upper tropospheric NOy background, last between 2 and $6 \mathrm{~s}$ and reach mixing ratios up to $6 \mathrm{nmol}$ $\mathrm{mol}^{-1} \mathrm{NOy}$ in the young contrail. Peaks in total CN number concentration in the young contrail, though less well defined because of more variable background, are up to $180 \mathrm{~cm}^{-3}$ above a background on the order of $300 \mathrm{~cm}^{-3}$. There are two peaks seen in the exhaust tracers at 0659:30 UT which are not matched by the presence of ice particles. This shows that either ice particles have evaporated in this particular small area or that there were differences in the dispersion of the exhaust gas plume and the contrail.

[20] In the older part of the contrail, between 0707 and 0712 UT, the measurements indicate four passages through the contrail, corresponding to plume ages of 11 to $20 \mathrm{~min}$. The geometric contrail width was estimated from the peak width, Falcon speed, and average angle of $15^{\circ}$ between the contrail and the Falcon flight track. This width evolved from about $350 \mathrm{~m}$ in the young contrail to about $1800 \mathrm{~m}$ in the aged contrail. This increase in width is within the upper range of values observed by Lidar from the ground in Southern Germany [Freudenthaler et al., 1995] and can be explained by the presence of a considerable amount of vertical shear of horizontal wind speed. From the measurements taken during ascent and descent shortly before and after the contrail measurement sequence, an average vertical gradient of the wind speed (Figure 1) component perpendicular to the Embraer flight track in the $300 \mathrm{~m}$ below flight level is found to be in the range $0.5-1.0 \times 10^{-2} \mathrm{~s}^{-1}$. Hence, a contrail of $100 \mathrm{~m}$ vertical dimension would spread within $15 \mathrm{~min}$ to a lateral width of roughly $1000 \mathrm{~m}$. This agrees with observation within a factor of less than 2 .

[21] Within the slightly aged contrail, NOy peaks, though lower and much broader than in the young contrail, remain detectable above the variable background, while CN enhancements are less pronounced. These sequences are well correlated with the peaks of the concentration of particles larger than $1 \mu \mathrm{m}$ (ConcF1, up to $130 \mathrm{~cm}^{-3}$ ). The increasing peak widths, between 15 and $35 \mathrm{~s}$, though dependent on the flight path angle of the Falcon relative to the contrail direction, reflect in general the dispersion of the contrail with time. Concentrations of particles larger than $3 \mu \mathrm{m}$ (ConcF3, up to $4 \mathrm{~cm}^{-3}$, see triangles in Figure 2) are much greater in the older plume than in the younger plume, indicating the growth of ice particles with time. The asymmetry parameter in the contrail is about 0.79 and the extinction coefficient peaks at $0.7 \mathrm{~km}^{-1}$, similar to the young contrail sequence.

[22] At the beginning of the investigation period (0643:00-0646:30 UT, see Figure 3), the measurements reveal the occurrence of ice crystals during a long sequence ( 3.5 min or $\sim 35 \mathrm{~km}$, marked by a solid line in Figure 2) with no short peaks or other trace of engine-emitted gases or particles. Compared to the slightly aged contrail, the concentration of particles larger than $1 \mu \mathrm{m}$ (ConcF1) is much smaller $\left(\sim 1 \mathrm{~cm}^{-3}\right)$ whereas the extinction coefficient and asymmetry parameter are similar $\left(\sim 1 \mathrm{~km}^{-1}\right.$ and 0.79 respectively). Although the visual observations made on board the aircraft did not allow to clearly distinguish between natural cirrus and contrail-induced cirrus, this flight sequence univocally measured in the frontal cirrus as evidenced from the mentioned satellite images. In this frontal cirrus, particles are unaffected or only slightly affected by direct aircraft emissions.

\subsection{Description of the Dynamical and Chemical Properties of the Contrail}

[23] Gerz et al. [1998] have described the dispersion of an exhaust plume in the wake flow of an aircraft. The secondary wake of an aircraft is expected to occur at the same altitude, while the primary wake associated with the vortex pair generated at the wing tips is dynamically forced to move downward. In this context, it may be particularly noted that the Falcon measurements of the Embraer-170 contrail were carried out at approximately the same altitude the Embraer170 was flying.

[24] The fact that the measured NOy and CN concentrations inside the young contrail are low (as explained below) triggered the question whether we measured inside the primary or secondary wake of the young contrail. Both pilots' observations as well as a video filmed from a forward pointing camera in the cockpit indicate that the Falcon repeatedly flew into the main part of the visible contrail. There was no indication of the presence of a visible contrail below the flight level. However, shear may have spread the vortex core relative to the secondary vortex such that they are located at different lateral positions in the contrail and not above each other. The young contrail was not visibly deformed by shear. For the old contrail, any deformation by wind shear could not be visually assessed because, optically, the contrail was too thin for such observations. During all contrail interceptions there were no clear indications of turbulence or temperature fluctuations.

[25] The humidity measurements made before the contrail encounter at lower altitudes indicate that it is very unlikely that a contrail associated to the primary wake of the aircraft at 100-200 m below cruising altitude could have dissolved quickly.

[26] Using the formulas given by Gerz et al. [2002] we estimate for the Embraer-170 aircraft a descent speed of the vortex pair of $1.9 \mathrm{~m} \mathrm{~s}^{-1}$ and a reference time scale of wake circulation of $10 \mathrm{~s}$. This implies that even in the case of the young contrail (at $2.5 \mathrm{~min}$ age, corresponding to 15 wake vortex circulations) measurements were made in the dispersion regime and that vortices should have dissolved. At this point the center of the primary wake of this aircraft is expected to be positioned approximately $120 \mathrm{~m}$ below the original flight altitude.

[27] The observed peaks in NOy during contrail penetrations can be used to estimate the plume dilution ratio according to Schumann et al. [1998]. The enhancement of NOy mixing ratios in the contrail above background range from 2.6 to $5.3 \mathrm{nmol} \mathrm{mol}^{-1}$ in the young contrail (neglecting the smallest NOy peaks where the visible contrail was probably only barely touched), and from 0.09 to 0.34 in the old contrail. Using an $\mathrm{NO}_{\mathrm{x}}$ emission index of $10 \mathrm{~g} \mathrm{~kg}^{-1}$ (in terms of $\mathrm{NO}_{2}$ mass) we estimate (according to equation (3) of Schumann et al. [1998]) a dilution factor of 1.2-2.4 $\times 10^{6}$ for the young contrail (2.5 min age), and 1.9-7.0 $\times 10^{7}$ for the old contrail (10-20 min age). This can be compared to the mean dilution versus plume age derived from a large set of observed dilution ratios of many aircraft types in a wide range of plume ages [Schumann et al., 1998]. The dilution ratios in 
the present study is significantly higher than the mean dilution derived by Schumann et al. [1998] though with a large scatter of factor $3-5$. The previous results imply dilution ratios of $3.8 \times 10^{5}$ at $2.5 \mathrm{~min}$ plume age, $1.3 \times$ $10^{6}$ at $11 \mathrm{~min}$, and $2 \times 10^{6}$ at $20 \mathrm{~min}$, i.e., roughly an order of magnitude greater than values inferred from the contrail measurement in this study. Such large dilution in young plumes was found also by Schlager et al. [1997]. The large dilution values suggest that the our measurements occurred mainly in the secondary wake of the young contrail.

[28] The measured mixing ratio is also at the low end of the mean mixing ratio that arises if all emitted NOx is spread uniformly over the contrail width and depth: For estimated values of contrail width $(b=1800 \mathrm{~m})$, contrail depth $(\mathrm{d}=$ $120 \mathrm{~m})$, NOx emission index $\left(\mathrm{EI}=10 \times 10^{-3}\right)$, fuel consumption rate $\left(m_{\mathrm{F}}=2.24 \mathrm{~kg} \mathrm{~km}^{-1}\right.$ for the Embraer-170 with 70 passengers), ambient density $\left(\rho=0.32 \mathrm{~kg} \mathrm{~m}^{-3}\right.$ at $\mathrm{p}=196 \mathrm{hPa}, \mathrm{T}=213 \mathrm{~K})$, mean aircraft speed $\left(\mathrm{V}=220 \mathrm{~m} \mathrm{~s}^{-1}\right)$, and ratio between molar masses for air and $\mathrm{NO}_{2}\left(\mathrm{M}_{\mathrm{air}} / \mathrm{M}_{\mathrm{NO} 2}=\right.$ 29/46), we compute a mean NOx mixing ratio increase $\Delta \mathrm{m}=$ $\left(\mathrm{M}_{\mathrm{NO} 2} / \mathrm{M}_{\text {air }}\right)$ EI $\mathrm{m}_{\mathrm{F}} /(\rho \mathrm{b} \mathrm{h} \mathrm{V})=1 \mathrm{nmol} \mathrm{mol}^{-1}$. Hence, the measured NOx peak mixing ratios in the aged contrail (up to $0.34 \mathrm{nmol} \mathrm{mol}^{-1}$ ) are a factor 3 below the mean mixing ratio to be expected. This also indicates that the measurements were taken in air masses at the boundary of the region (the primary vortex) over which most of the NOx emissions were mixed.

[29] The ratio between NOy peak values (about $0.3 \mathrm{nmol}$ $\mathrm{mol}^{-1}$ ) and $\mathrm{CN}$ peak values (about $20 \mathrm{~cm}^{-3}$ ) can be converted into an emission index $\mathrm{EI}_{\mathrm{CN}}$ for particles larger $10 \mathrm{~nm}$ of $1.4 \times 10^{15} \mathrm{~kg}^{-1}$ per $\mathrm{kg}$ of burnt fuel. This computation is based on $\mathrm{EI}_{\mathrm{CN}}=\mathrm{EI}_{\mathrm{NOx}} \mathrm{CN} \mathrm{M}$ _air $/\left(\mathrm{M}_{\mathrm{NO} 2} * \mathrm{NO}_{\mathrm{y}} \rho\right)$. This particle emission index is consistent with the range of $0.34-2.1 \times 10^{15} \mathrm{~kg}^{-1}$ found by Schröder et al. [2000b] during measurements behind a B737 for particles larger 5 to $14 \mathrm{~nm}$ in an evaporating contrail. Hence, the amount of $\mathrm{CN}$ and NOy found is consistent in magnitude with previous measurements.

[30] The visual observations suggest that the measurements covered the main part of the contrail and suggest that the contrail optical and microphysical ice particle data obtained in this study are representative of the visible persistent contrail created by the Embraer-170 after the wake vortices have decayed. The relatively low peak NOy mixing ratio values and the measurement altitudes near or slightly above the altitude of the contrail forming aircraft suggest that the measurements were performed in the secondary part of the contrail remaining above the sinking primary vortex.

[31] In section 3.3 we discuss the microphysical and optical properties of the Embraer-170 contrail at different stages of plume evolution (between 2.5 and 20 min age) and compare the results to the natural cirrus observed shortly before the probing of the contrail.

\subsection{Young Contrail Microphysical and Optical Properties}

\subsubsection{Results}

[32] Figure 4 illustrates the results from the young (visible) contrail sampled between 0655 and 0702 UT (see Figure 3). Figure 4a (left) displays the PMS FSSP-300 particle size distribution (averaged over the peaks during the corresponding flight sequence). Figure $4 \mathrm{a}$ (right) represents the average scattering phase function (without normalization) measured by the polar nephelometer (solid circle symbols) and the theoretical phase function (cross symbols) calculated from the FSSP-300 size distribution assuming spherical ice particles. The FSSP-300 and polar nephelometer measurements are likely not affected by ice crystal-shattering effects since the particle sizes are less than $100 \mu \mathrm{m}$. The mean values of the parameters, summarized in Table 1, indicate ice particle concentration (for $\mathrm{D}>1 \mu \mathrm{m}$ ), ice water content, extinction coefficient and effective diameter of $68.3 \mathrm{~cm}^{-3}, 0.9 \mathrm{mg} \mathrm{m}^{-3}$, $0.48 \mathrm{~km}^{-1}$ and $6 \mu \mathrm{m}$, respectively. These results are similar to those obtained by Baumgardner and Gandrud [1998] in a young contrail at about the same temperature. Much greater ice particle concentrations (more than $1000 \mathrm{~cm}^{-3}$ ) have been reported by Schröder et al. [2000a] for contrails of up to $150 \mathrm{~s}$ age. Nevertheless, these concentration values depend on the threshold of the lower size cutoff ( $1 \mu \mathrm{m}$ in this study) and the measurements in this size range may suffer from substantial uncertainties because of particle characterization with optical probes. Counting numerous small haze droplets which are interstitial aerosol rather than growing ice cannot be excluded.

[33] Figure 4a (right) shows that the calculated phase function agrees quite well with the observation from the polar nephelometer. In other words, the modeled value of the extinction coefficient matches well with the measured one, and the phase functions are closely related at forward angles near $\theta \approx 15^{\circ}$ and at side angles near $\theta \approx 100^{\circ}$. At the same time, the model slightly overestimates the scattered energy at forward angles $\left(6-10^{\circ}\right)$ and around $50^{\circ}$. The differences may result from various reasons as discussed in section 3.3.2.

\subsubsection{Discussion}

[34] Two points could explain these differences: first the FSSP size calibration and cut-off size and second the real refractive index of the considered particles.

\subsubsection{FSSP-300 Size Calibration and Cutoff Size}

[35] We recall that the size response of the FSSP-300 has been determined for ice spheres. Sizing uncertainties are less than $25 \%$ for measurements of nonspherical particles with an uncertain index of refraction [Baumgardner et al., 1989]. Additionally, the use of spherical ice rather than water induces uncertainties of about $10 \%$. The most critical issue concerns the cutoff diameter (set at Dc $=1.0 \mu \mathrm{m}$ ) at which both instruments (FSSP-300 and polar nephelometer) give a similar response (in terms of scattering phase function). The particles with the smallest sizes $(\mathrm{D}<\mathrm{Dc})$ are not considered in this study. These particles contribute only $10 \%$ to the total extinction and therefore do not significantly affect the optical properties that can be measured by the polar nephelometer (i.e., the subsequent response is within the instrumental errors [see Shcherbakov et al., 2005]). On the contrary, a slight increase in the cutoff diameter $(\Delta \mathrm{Dc}=+1.0 \mu \mathrm{m}$ or $+50 \%$ of sizing error) induces large differences (more than 100\%) between the theoretical (FSSP-300) and the measured (polar nephelometer) phase functions. The theoretical values are significantly smaller than the observed values; that is, the computed value of the extinction coefficient (FSSP-300) is less than half as large. This is explained by the narrowness of the size distribution (see Figure 4a), which leads to the steep increase in the cumulative frequency distribution of the extinction in a diameter range between 1 and $2 \mu \mathrm{m}$ as displayed in Figure 5. In other words, about $80 \%$ of the extinction is due to particles smaller than $5 \mu \mathrm{m}$. It should also 

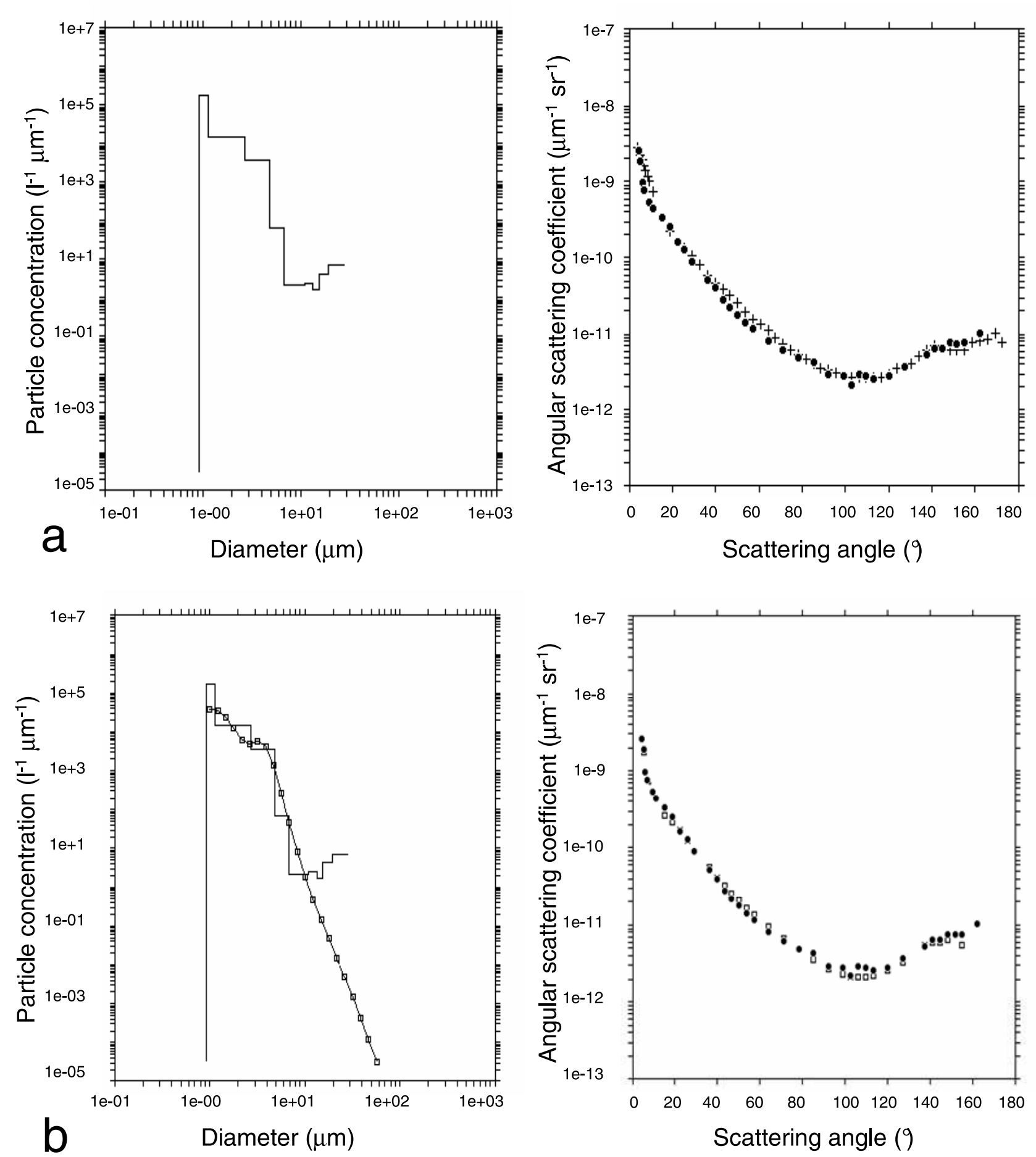

Figure 4. Properties of the young contrail sampled between 0655 and 0702 (UT) at the 12,300 m $\left(-60^{\circ} \mathrm{C}\right.$ ) level. (a) (left) FSSP-300 and 2D-C particle size distributions. (right) Measured (polar nephelometer, solid circle symbols) and theoretical (cross symbols) scattering phase functions, the latter being calculated from the FSSP-300 size distribution and assuming ice spheres. (b) (left) Direct particle size distribution (FSSP-300 and 2D-C) and retrieved particle spectrum (open square symbols) from the measured scattering phase function. (right) Measured (solid circle symbols) and inverse (open square symbols) scattering phase functions. 
Table 1. Properties of Young Contrail, Aged Contrail, and Natural Cirrus Measured in a Similar Environment ${ }^{\mathrm{a}}$

\begin{tabular}{|c|c|c|c|c|c|c|c|c|c|c|c|c|c|}
\hline & $\begin{array}{c}\text { Temperature } \\
\left({ }^{\circ} \mathrm{C}\right)\end{array}$ & $\begin{array}{c}\text { Altitude } \\
(\mathrm{m})\end{array}$ & $\begin{array}{l}\text { RHi } \\
(\%)\end{array}$ & $\begin{array}{c}\text { Conc F1 } \\
\left(\mathrm{cm}^{-3}\right)\end{array}$ & $\begin{array}{c}\text { Conc F3 } \\
\left(\mathrm{cm}^{-3}\right)\end{array}$ & $\begin{array}{c}\text { Conc 2D } \\
\left(\mathrm{L}^{-1}\right)\end{array}$ & $\begin{array}{c}\text { IWC } \\
\left(\mathrm{mg} \mathrm{m}^{-3}\right)\end{array}$ & $\begin{array}{c}\text { IWC D > } 25 \\
\left(\mathrm{mg} \mathrm{m}^{-3}\right)\end{array}$ & $\begin{array}{c}\begin{array}{c}\text { Ext } \\
\left(\mathrm{km}^{-1}\right)\end{array} \\
\end{array}$ & $\begin{array}{c}\text { Ext } \mathrm{D}>25 \\
\left(\mathrm{~km}^{-1}\right)\end{array}$ & $\begin{array}{l}D_{\text {eff }} \\
(\mu \mathrm{m})\end{array}$ & $\begin{array}{c}\mathrm{D}_{\text {eff }} \mathrm{D}>25 \\
(\mu \mathrm{m})\end{array}$ & $\mathrm{g}$ \\
\hline Young contrail & -60 & 11,900 & 118 & 68.3 & 0.2 & - & 0.9 & - & 0.48 & - & 6 & - & 0.827 \\
\hline Slightly aged contrail & -60 & 11,900 & 121 & 18.3 & 0.9 & - & 1.0 & - & 0.29 & - & 11 & - & 0.787 \\
\hline Natural cirrus & -57 & 11,400 & 125 & 1.4 & 0.1 & 150 & 2.0 & 1.5 & 0.30 & 0.21 & 25 & 28 & 0.790 \\
\hline
\end{tabular}

${ }^{\mathrm{a}}$ Mean values of temperature, flight altitude, and relative humidity (over ice) are given. The microphysical and optical properties are indicated in terms of concentration (Conc) of particles greater than $1 \mu \mathrm{m}(\mathrm{F} 1), 3 \mu \mathrm{m}(\mathrm{F} 3)$, and $25 \mu \mathrm{m}(2 \mathrm{D})$. The extinction coefficient (Ext), ice water content (IWC), and effective diameter $\left(\mathrm{D}_{\text {eff }}\right)$ are reported for particles larger than $1 \mu \mathrm{m}$ and $25 \mu \mathrm{m}$ (labeled $\left.\mathrm{D}>25\right)$. The asymmetry parameter $(\mathrm{g})$ is indicated in the last column.

be noticed that the contribution of particles larger than $10 \mu \mathrm{m}$ represents only a few percent of the total extinction of the young contrail.

\subsubsection{Refractive Index of the Particles}

[36] Whereas the response of the FSSP-300 is not significantly affected by either the water or ice hypothesis (see above), the best fit between the theoretical (FSSP-300) and the measured (polar nephelometer) phase functions (particularly in the range of the scattering angle between $50^{\circ}$ and $80^{\circ}$ ) is found assuming an ice refractive index $(m=1.31)$ in the direct Mie calculations. Furthermore, our sensitivity tests show that the effect of both $\mathrm{H}_{2} \mathrm{SO}_{4}$ solution droplets and inclusions of absorbing material (soot) on the visible optical properties of the young contrails was less significant than the errors of the polar nephelometer measurements. In other words, the values of the real and the imaginary parts of the refractive index are lower than 1.35 and $10^{-3}$, respectively.

[37] In conclusion of these two discussed points, none of the aforementioned hypotheses may fully explain the slight discrepancies (Figure 4a) between the observations and the theory, the latter being based on the perfect spherical particle hypothesis. A slight deviation from the spherical shape may finally explain the observations. Indeed, ice crystals in a younger contrail (1 min growing time) have already been evidenced by Goodman et al. [1998] at a similar temperature $\left(-61^{\circ} \mathrm{C}\right)$. The particles had a unimodal size distribution with an effective diameter of about $4 \mu \mathrm{m}$ but, in contrast to our observations, the few examples shown in that study indicate shapes greatly deviating from a quasi-spherical form, i.e., hexagonal plates, columns and triangles. On the other hand, the replica image observations of Schröder et al. [2000a] show ice particles that are almost spherical. Our results may support the interpretation of Sassen [1979] who explained the iridescence in young contrails by using the diffraction-corona theory and assuming monodisperse quasi-spherical (ice or liquid) cloud particle distribution of 1-3 $\mu \mathrm{m}$ diameter. The fact that no red band corona was observed with the polar nephelometer in the $10^{\circ}-20^{\circ}$ range of the scattering angle may be due to the relative spreading of the particle size distribution (see Figure 4).

[38] The ice sphere hypothesis permits the use of the inversion technique developed by Dubovik [2004]. In Figure 4b (left), we may see the direct FSSP-300 and 2D-C observations along with the particle size spectrum retrieved on the

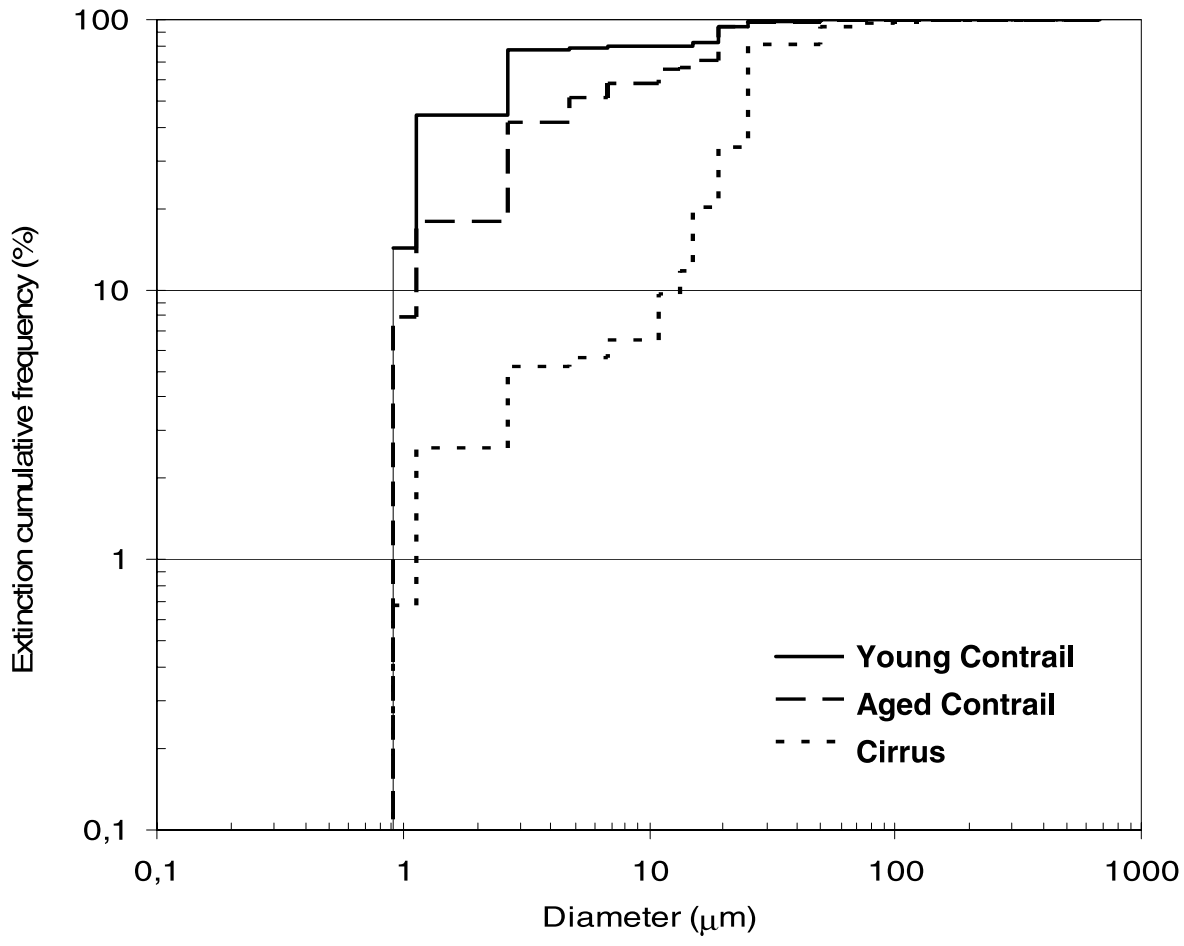

Figure 5. Cumulative frequencies of the extinction coefficient for the three considered cloud cases: young contrail, aged contrail, and natural cirrus. 

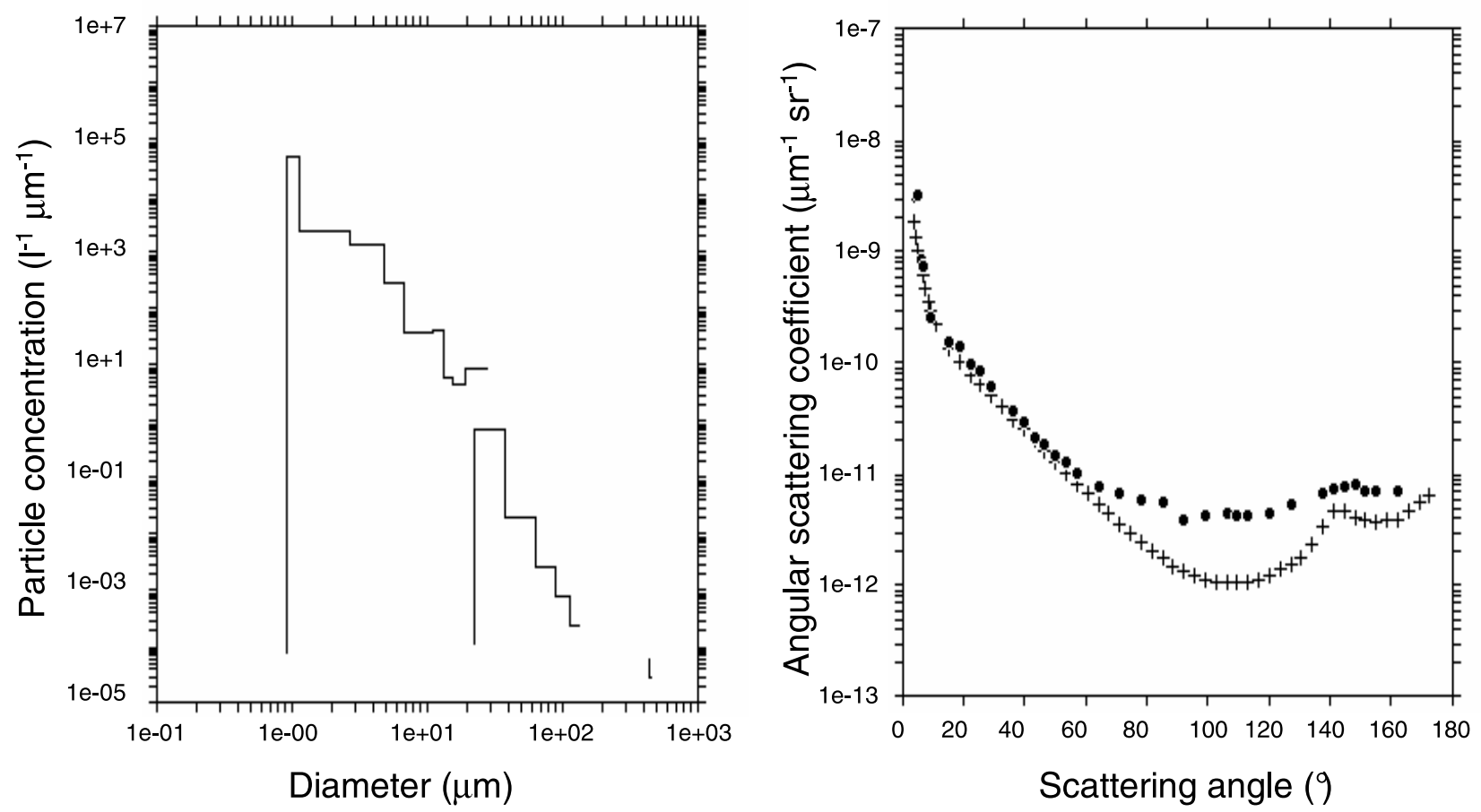

Figure 6. Properties of the aged contrail sampled between 0707 and 0711 (UT) at the $12,300 \mathrm{~m}\left(-60^{\circ} \mathrm{C}\right)$ level. (left) FSSP-300 and 2D-C particle size distributions. (right) Measured (polar nephelometer, solid circle symbols) and theoretical (cross symbols) scattering phase functions, the latter being calculated from the FSSP-300 size distribution and assuming ice spheres.

basis of the scattering phase function measured by the polar nephelometer. Compared to the direct observations, the retrieved size spectrum shows roughly the same mode size and spreading for particle diameters smaller than $10 \mu \mathrm{m}$. The few particles larger than $10 \mu \mathrm{m}$ measured by the FSSP-300 contribute only slightly to the optical properties even when assumed to be irregular shaped ice crystals. This is supported by the results in Figure $4 \mathrm{~b}$ (right), which show a close agreement between the measured (solid circle symbols) and the inverse (open square symbols) scattering phase functions. The bimodal feature of the inverse size distribution (Figure $4 \mathrm{~b}$ ) is quite robust with respect to small variations of the observations. Nevertheless, we cannot rule out that the smallest mode at $1-2 \mu \mathrm{m}$ is actually aerosol haze because the changes in retrievals for different refractive index values are smaller than the errors of the polar nephelometer measurements.

\subsection{Slightly Aged Contrail Properties}

[39] The results concerning the slightly aged contrail (1120 min age) sampled between 0707 and 0712 UT (see Figure 3) are displayed in Figure 6 similarly to those in Figure 4a. The mean values of the parameters are summarized in Table 1. As for the young contrail we assume that the shattering effects do not significantly affect these results since the particles sizes are less than $100 \mu \mathrm{m}$. The results clearly exhibit differences between the aged and young contrail properties. The aged contrail shows a significant spreading of the particle size distribution (Figure 6, left)), which is possibly caused by turbulent dilution and water uptake within the contrail plume. Indeed, the effective diameter increases to $11 \mu \mathrm{m}$, the concentration ConcF1 (D > 1 $\mu \mathrm{m})$ drops to $18.3 \mathrm{~cm}^{-3}$, whereas
ConcF3 (D $>3 \mu \mathrm{m}$ ) increases to $0.9 \mathrm{~cm}^{-3}$ for the three last contrail measurements. Approximately $80 \%$ of the total extinction is made up of particles with sizes smaller than $10 \mu \mathrm{m}$ (compared with $5 \mu \mathrm{m}$ in the previous case, see Figure 5). These small particles dominate the optical properties. Particles larger than $25 \mu \mathrm{m}$ (2D-C data) contribute only a few percent $(5 \%)$ to the total extinction. The results are similar to those reported by Schröder et al. [2000a] for contrails in the dispersion regime under similar conditions.

[40] The observed and the theoretical phase functions (see Figure 6, right) show close agreement at the forward scattering angles $\left(5^{\circ}-50^{\circ}\right)$. Because most of the extinction is caused by scattering at forward angles, this does undoubtedly prove the consistency of data from the FSSP-300 and polar nephelometer instruments. Much greater energy is scattered at side angles than may normally be expected for spherical particles. As is known, scattering by aspherical ice particles is considerably greater than by spherical particles at side scatter angles ranging between 80 and $120^{\circ}$, leading to a significantly smaller $g$ value $(0.787$, see Table 1$)$. This indicates that the shape of most of the observed ice particles at sizes smaller than $10 \mu \mathrm{m}$ strongly deviates from the spherical form. Similar observations were reported by Gayet et al. [2006] with occurrence of small irregular ice crystals in wave clouds and by Baumgardner et al. [2005] but, in this instance, for larger particle sizes $(30 \mu \mathrm{m})$. Unfortunately, the transition from quasi-spherical shapes to irregular ice particles in the atmosphere is poorly understood. This transition may depend strongly on the ambient supersaturation and the aerosol cores (e.g., liquid or solid, water or solution droplets) upon which the ice particles nucleate. 

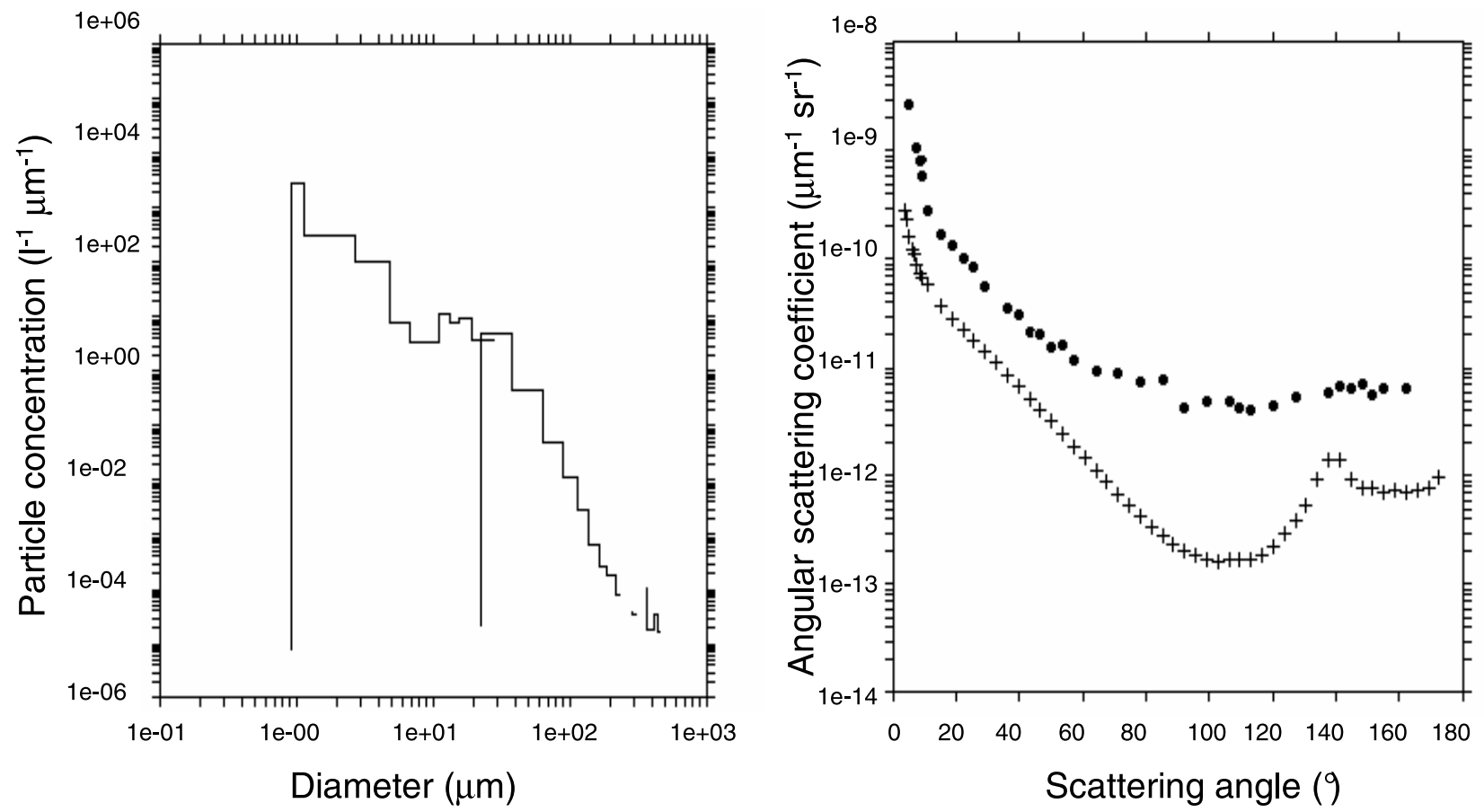

Figure 7. Same as Figure 6. Properties of the natural cirrus sampled between 0643 and 0646:30 (UT) at the $11,800 \mathrm{~m}\left(-57^{\circ} \mathrm{C}\right)$ level.

\subsection{Cirrus Cloud Properties}

[41] Figure 7 displays the results obtained in the frontal cirrus sampled between 0643:00 and 0646:30 UT (see Figure 3). The ice particle concentrations ( $\mathrm{ConcF} 1$ and ConcF3), ice water content, extinction and effective diameter are $1.4 \mathrm{~cm}^{-3}, 0.1 \mathrm{~cm}^{-3}, 2 \mathrm{mg} \mathrm{m}{ }^{-3}, 0.3 \mathrm{~km}^{-1}$ and $25 \mu \mathrm{m}$, respectively (see Table 1 ). We note in passing that without the contribution of the small particles ( $\mathrm{D}<25 \mu \mathrm{m}$, see Table 1) the bulk parameters (Extinction and IWC) are reduced by about $25-30 \%$. These values give estimates of the worse effects on the measurements assuming that all the small particles are due to the shattering of ice crystals. Therefore, the subsequent contamination of the FSSP and polar nephelometer measurements is probably not very important $(<25 \%)$ since the maximum dimension statistically measured with significance is about $200 \mu \mathrm{m}$ (larger particles with $\mathrm{D} \sim 350 \mu \mathrm{m}$ are detected from time to time).

[42] The large difference between ConcF1 and $\mathrm{ConcF} 3$ shows a strong size dependence of the ice particle concentration. Compared to the aged contrail properties, the concentration of particles larger $3 \mu \mathrm{m}(\mathrm{ConcF} 3)$ is smaller $\left(0.1 \mathrm{~cm}^{-3}\right.$ against $\left.0.9 \mathrm{~cm}^{-3}\right)$ while the concentration of particles larger $\mathrm{D}>25 \mu \mathrm{m}$ is higher than in the aged contrail $\left(150 \mathrm{~L}^{-1}\right.$ versus $\left.21 \mathrm{~L}^{-1}\right)$. The large particles, with diameter larger than $20 \mu \mathrm{m}$, contribute about $80 \%$ of the total extinction (see Figure 5). Hence, the larger particles dominate the optical properties in this case. This is confirmed by the differences between the measured phase function and the phase function calculated from the FSSP-300 size distribution assuming ice spheres (see Figure 7, right). Neither have peak features at large scattering angles. As for the slightly aged contrail, the featureless measured phase function with a corresponding $g$ value of 0.790 indicates the presence of ice crystals with irregular shape as exemplified in Figure 8. It is interesting to point out that despite different distributions of the extinction coefficient (see Figure 5) the resultant scattering phase functions of the aged contrail and the natural cirrus do not differ significantly and show similar extinction values $\left(0.30 \mathrm{~km}^{-1}\right)$. Similar conclusions about rather uniform

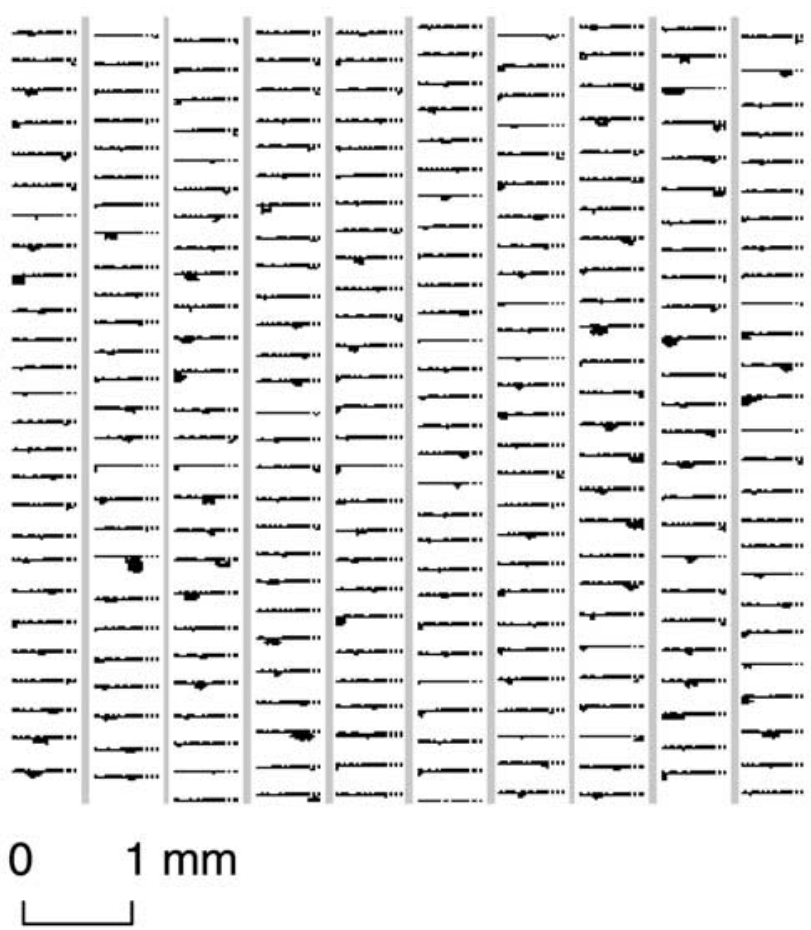

Figure 8. Examples of ice crystals measured by the PMS 2D-C probe in the natural cirrus at 0644:30 (UT). 
particle scattering properties have been drawn from the analysis of midlatitude wave ice clouds and cirrus [Baumgardner and Gandrud, 1998; Gayet et al., 2004]. This may be explained by the highly irregular shape of the ice crystals resulting in a featureless scattering phase function regardless of particle size.

[43] The mean values of the cirrus properties (see Table 1) obtained in a dense air traffic region are notably similar to the mean values of midlatitude cirrus observed over the North Atlantic and Western Europe during INCA [see Gayet et al., 2004, Table 3]. The role of aircraft exhaust in modifying cirrus formation is still an open question but regional studies observed elevated ice particle concentrations and reduced mean particle sizes in polluted regions [Kristensson et al., 2000; Gayet et al., 2004]. Hence, there are indications that cirrus cloud properties could be contaminated near flight corridors. However, our data show no specific contribution from aviation emissions to the frontal cirrus clouds that we observed.

\section{Summary and Conclusions}

[44] This paper presents a case study of measurements of the optical and microphysical properties of a young contrail, a slightly aged contrail and a frontal cirrus cloud sampled in a similar thermodynamical environment (near $-60^{\circ} \mathrm{C}$ and $12 \mathrm{~km}$ altitude). The observations cover the evolution of the contrail from a midsized airliner during its aging from $2.5 \mathrm{~min}$ to $20 \mathrm{~min}$. The measurements in the slightly aged contrail might have been taken mainly in the secondary wake left behind the sinking (or by wind shear laterally displaced) primary wake core. As has been shown in several recent studies, the sampling methods used in this study may be affected by particle shattering at the instrument inlets. However, as very few ice particles larger than $100 \mu \mathrm{m}$ in diameter were observed, we expect that the shattering effects are of minor importance for the present results. Future studies require instruments avoiding shattering for better observations in natural cirrus with large ice particles.

[45] The interpretation of the observations in terms of size calibration and refractive-index hypothesis of both FSSP-300 and polar nephelometer responses leads to the conclusion that quasi-spherical ice particles with diameter smaller than $5 \mu \mathrm{m}$ control the optical properties of the contrail shortly after formation. Fresh contrail particles of similar sizes have been observed by Baumgardner and Gandrud [1998] and Schröder et al. [2000a]. Such small particles were not observed in natural cirrus clouds at midlatitudes, e.g., during INCA [Gayet et al., 2004]. Only the few observations by Sassen et al. [1998] of vague glories observed in an orographic wave cloud around $-50^{\circ} \mathrm{C}$ indicated backscattering of light from slightly aspherical ice particles. However, these ice particles were larger (around $10 \mu \mathrm{m}$ ) than those measured in this study.

[46] The particle size distribution retrieved from the measured scattering phase function (polar nephelometer) agrees very well with the direct measurements (FSSP-300) for mode size and size spreading for particles with diameter smaller than $10 \mu \mathrm{m}$. These results support the assumption that the particles in the young contrail have a quasi-spherical shape. This is in accordance with the interpretation of Sassen [1979], explaining iridescence in young contrails by small spherical particles, and with the replica images of contrail particles presented by Schröder et al. [2000a], but contradicts the observations in fresh contrails observed by Goodman et al. [1998], who showed a mixture of small particles with hexagonal plate, column and triangle shapes. The reasons for the differences in observed ice crystal habits are not known. The subsequent effects of particle shapes on contrail growth and lifetime are probably small since they are mainly controlled by humidity and dynamical fields [Minnis et al., 1998].

[47] In the slightly aged contrail case, a larger particle size spreading is observed and may be explained by turbulent dilution and high supersaturation in the plume during aircraft vortex breakup. The particles with sizes smaller than $10 \mu \mathrm{m}$ contribute about $80 \%$ to the total extinction and therefore dominate the optical properties. The contribution of particles larger than $25 \mu \mathrm{m}$ represents only a few percent (5\%) of the total extinction. The FSSP-300 and polar nephelometer measurements are consistent as highlighted by a close agreement between the observed and computed phase functions at forward scattering angles. However, the assumption of spherical particles leads to much greater energy being scattered at side angles compared to the actual measurement with the polar nephelometer. This indicates that the shape of most of the observed ice particles of sizes smaller than $10 \mu \mathrm{m}$ in this aged contrails strongly deviates from the spherical form.

[48] Microphysical properties of contrails reported mainly from SULFUR and SUCCESS experiments (see Baumgardner and Gandrud [1998], Schröder et al. [2000a] and the review by Schumann [2002, Figure 11.5]) shows that at similar temperatures IWC values range between about 1 and $7 \mathrm{mg}$ $\mathrm{m}^{-3}$. Our ice water content measurements (which may be affected by the shortcomings discussed in $\S 2.1$ ), appear small although within the range of previous observations (see Table 1).

[49] The mean particle properties in the frontal cirrus are similar to those of midlatitude cirrus observed over the North Atlantic during the INCA experiment [Gayet et al., 2004]. In such cirrus, with many particles larger than $20 \mu \mathrm{m}$, extinction is dominated by the fraction of large particles (see Figure 5). As for the slightly aged contrail, the measured phase function is featureless without any significant peaks which would indicate the presence of ice crystals with irregular shape. It is interesting to underline that despite different contributions to the extinction coefficient, the resultant scattering phase functions for the slightly aged contrail and the natural cirrus do not differ significantly.

[50] It should be noted that this study reports on a case of contrail and cirrus property observations at a limited temperature range. It may well be that the ice particles would be larger at slightly higher temperatures, as observed for natural cirrus. Furthermore, the probed contrail covered only ages up to $15-20 \mathrm{~min}$. As individual contrails have been shown to persist for more than $17 \mathrm{~h}$ [Minnis et al., 1998], the measurements cover only a small portion of the full potential contrail life cycle. Cleary, more systematic observations are needed to expand the range of life times and thermodynamic conditions.

[51] Acknowledgments. PAZI-2 is a research project funded and coordinated by DLR and supported by the Helmholtz-Gemeinschaft Deutscher Forschungszentren. This work was partially funded by DLR and by a grant from a CNRS-INSU program. We are very grateful to the members of the DLR who operated the Falcon aircraft during the experiment. 
We acknowledge the team at the Air Traffic Control of Karlsruhe for their assistance. We thank J.-F. Fournol and C. Gourbeyre (LaMP) and A. Roiger (DLR) for their technical assistance. We acknowledge T. Gerz (DLR) for fruitful discussions, S. Unterstrasser for contrail age calculations, M. VázquezNavarro for carefully analyzing MSG images for this study, and K. James, who reviewed the manuscript. Anonymous reviewers made important comments that strengthened the manuscript.

\section{References}

Atlas, D., Z. Wang, and D. P. Duda (2006), Contrails to cirrus-Morphology, microphysics, and radiative properties, J. Appl. Meteorol. Climatol., 45, 5-19, doi:10.1175/JAM2325.1.

Baumgardner, D., and B. E. Gandrud (1998), A comparison of the microphysical and optical properties of particles in an aircraft contrail and mountain wave cloud, Geophys. Res. Lett., 25, 1129-1132, doi:10.1029/ 98GL00035.

Baumgardner, D., and A. Korolev (1997), Airspeed corrections for optical array probe sample volumes, J. Atmos. Oceanic Technol., 14, 12241229, doi:10.1175/1520-0426(1997)014<1224:ACFOAP>2.0.CO;2.

Baumgardner, D., J. E. Dye, and B. W. Gandrud (1989), Calibration of the Forward Scattering Spectrometer Probe used on the ER-2 during the Airborne Antarctic Ozone Experiment, J. Geophys. Res., 94, 16,47516,480, doi:10.1029/JD094iD14p16475.

Baumgardner, D., J. E. Dye, B. W. Gandrup, and R. G. Knollenberg (1992), Interpretation of measurements made by the Forward Scattering Spectrometer Probe (FSSP-300) during the Airborne Arctic Stratosphere Expedition, J. Geophys. Res., 97, 8035-8046.

Baumgardner, D., H. Chepfer, G. B. Raga, and G. L. Kok (2005), The shapes of very small cirrus particles derived from in situ measurements, Geophys. Res. Lett., 32, L01806, doi:10.1029/2004GL021300.

Busen, R., and A. L. Buck (1995), A high-performance hygrometer for aircraft use: Description, installation, and flight data, J. Atmos. Oceanic Technol., 12, 73 -84, doi:10.1175/1520-0426(1995)012<0073:AHPHFA> 2.0.CO;2.

Dubovik, O. (2004), Optimization of numerical inversion in photopolarimetric remote sensing, in Photopolarimetry in Remote Sensing, edited by G. Videen, Y. Yatskiv, and M. Mishchenko, pp. 65-106, Kluwer Acad, Dordrecht, Netherlands.

Field, P. R., R. Wood, P. R. A. Brown, P. H. Kaye, E. Hirst, R. Greenaway, and J. Smith (2003), Ice particle interarrival times measured with a fast FSSP, J. Atmos. Oceanic Technol., 20, 249-261, doi:10.1175/15200426(2003)020<0249:IPITMW>2.0.CO;2.

Field, P. R., A. J. Heymsfield, and A. Bansemer (2006), Shattering and interarrival times measured by optical array probes in ice clouds, J. Atmos. Oceanic Technol., 23, 1357-1371, doi:10.1175/JTECH1922.1.

Freudenthaler, V., F. Homburg, and H. Jäger (1995), Contrail observations by ground-based scanning lidar: Cross-sectional growth, Geophys. Res. Lett., 22, 3501-3504, doi:10.1029/95GL03549.

Gayet, J.-F., O. Crépel, J.-F. Fournol, and S. Oshchepkov (1997), A new airborne polar nephelometer for the measurements of optical and microphysical cloud properties. Part I: Theoretical design, Ann. Geophys., 15, 451-459, doi:10.1007/s00585-997-0451-1.

Gayet, J.-F., F. Auriol, S. Oshchepkov, F. Schröder, C. Duroure, G. Febvre, J.-F. Fournol, O. Crépel, P. Personne, and D. Daugereon (1998), In situ measurements of the scattering phase function of stratocumulus, contrails and cirrus, Geophys. Res. Lett., 25, 971-974, doi:10.1029/98GL00541.

Gayet, J.-F., F. Auriol, A. Minikin, J. Ström, M. Seifert, R. Krejci, A. Petzold, G. Febvre, and U. Schumann (2002a), Quantitative measurement of the microphysical and optical properties of cirrus clouds with four different in situ probes: Evidence of small ice crystals, Geophys. Res. Lett., 29(24), 2230, doi:10.1029/2001GL014342.

Gayet, J.-F., S. Asano, A. Yamazaki, A. Uchiyama, A. Sinyuk, O. Jourdan, and F. Auriol (2002b), Two case studies of winter continental-type water and mixed-phase stratocumuli over the sea: 1. Microphysical and optical properties, J. Geophys. Res., 107(D21), 4569, doi:10.1029/2001JD001106.

Gayet, J.-F., J. Ovarlez, V. Shcherbakov, J. Ström, U. Schumann, A. Minikin, F. Auriol, A. Petzold, and M. Monier (2004), Cirrus cloud microphysical and optical properties at southern and northern midlatitudes during the INCA experiment, J. Geophys. Res., 109, D20206, doi:10.1029/ 2004JD004803.

Gayet, J.-F., V. Shcherbakov, H. Mannstein, A. Minikin, U. Schumann, J. Ström, A. Petzold, J. Ovarlez, and F. Immler (2006), Microphysical and optical properties of midlatitude cirrus clouds observed in the Southern Hemisphere during INCA, Q. J. R. Meteorol. Soc., 132, 2719-2748, doi:10.1256/qj.05.162.

Gerbig, C., D. Kley, A. Volz-Thomas, J. Kent, K. Dewey, and D. S. McKenna (1996), Fast response resonance fluorescence CO measurements aboard the C-130: Instrument characterization and measurements made during the North Atlantic Regional Experiment 1993, J. Geophys. Res., 101, 29,229-29,238, doi:10.1029/95JD03272.
Gerz, T., T. Dürbeck, and P. Konopka (1998), Transport and effective diffusion of aircraft emissions, J. Geophys. Res., 103, 25,905-25,913, doi:10.1029/98JD02282.

Gerz, T., F. Holzäpfel, and D. Daracq (2002), Commercial aircraft wake vortices, Prog. Aerosp. Sci., 38, 181-208, doi:10.1016/S0376-0421(02)00004-0.

Goodman, J., R. F. Pueschel, E. J. Jensen, S. Verma, G. V. Ferry, S. D. Howard, S. A. Kinne, and D. Baumgardner (1998), Shape and size of contrails ice particles, Geophys. Res. Lett., 25, 1327-1330, doi:10.1029/ 97GL03091.

Heymsfield, A. J. (1972), Ice crystal terminal velocities, J. Atmos. Sci., 29, 1348-1366, doi:10.1175/1520-0469(1972)029<1348:ICTV>2.0.CO;2.

Heymsfield, A. J. (2007), On measurements of small ice particles in clouds, Geophys. Res. Lett., 34, L23812, doi:10.1029/2007GL030951.

Heymsfield, A. J., and J. L. Parrish (1978), A computational technique for increasing the effective sampling volume of the PMS two-dimensional particle size spectrometer, J. Appl. Meteorol., 17, 1566-1572, doi:10.1175/1520-0450(1978)017<1566:ACTFIT>2.0.CO;2.

Heymsfield, A. J., R. P. Lawson, and G. W. Sachse (1998), Growth of ice crystals in a precipitating contrail, Geophys. Res. Lett., 25, 1335-1338, doi:10.1029/98GL00189.

Korolev, A., and G. A. Isaac (2005), Shattering during sampling by OAPs and HVPS. Part I: Snow particles, J. Atmos. Oceanic Technol., 22, $528-$ 543, doi:10.1175/JTECH1720.1.

Kristensson, A., J.-F. Gayet, J. Ström, and F. Auriol (2000), In situ observations of a reduction in effective crystal diameter in cirrus clouds near flight corridors, Geophys. Res. Lett., 27, 681-684, doi:10.1029/1999GL010934.

Lawson, R. P., A. J. Heymsfield, S. M. Aulenbach, and T. L. Jensen (1998), Shapes, sizes and light scattering properties of ice crystals in cirrus and a persistent contrail during SUCCESS, Geophys. Res. Lett., 25, $1331-$ 1334, doi:10.1029/98GL00241.

Locatelli, J. D., and P. V. Hobbs (1974), Fall speeds and masses of solid precipitation particles, J. Geophys. Res., 79, 2185-2197, doi:10.1029/ JC079i015p02185.

McFarquhar, G. M., J. Um, M. Freer, D. Baumgardner, G. L. Kok, and G. Mace (2007), Importance of small ice crystals to cirrus properties: Observations from Tropical Warm Pool International Cloud Experiment (TWP-ICE), Geophys. Res. Lett., 34, L13803, doi:10.1029/ 2007GL029865.

Minnis, P., D. F. Young, D. P. Garber, L. Nguyen, W. L. Smith Jr., and R. Palikonda (1998), Transformation of contrails into cirrus during SUCCESS, Geophys. Res. Lett., 25, 1157-1160, doi:10.1029/ 97GL03314.

Petzold, A., et al. (1997), Near-field measurements on contrail properties from fuels with different sulfur content, J. Geophys. Res., 102, 29,86729,880, doi:10.1029/97JD02209.

Petzold, A., et al. (2007), Perturbation of the European free troposphere aerosol by North American forest fire plumes during the ICARTT-ITOP experiment in summer 2004, Atmos. Chem. Phys., 7, 5105-5127.

Sassen, K. (1979), Iridescence in an aircraft contrail, J. Opt. Soc. Am., 69, 1080-1083, doi:10.1364/JOSA.69.001080

Sassen, K., W. P. Arnott, J. M. Barnett, and S. Aulenbach (1998), Can cirrus clouds produce glories?, Appl. Opt., 37, 1427-1433, doi:10.1364/ A0.37.001427

Schlager, H., P. Konopka, P. Schulte, U. Schumann, H. Ziereis, F. Arnold, M. Klemm, D. E. Hagen, P. D. Whitefield, and J. Ovarlez (1997), In situ observations of air traffic emission signatures in the North Atlantic flight corridor, J. Geophys. Res., 102, 10,739-10,750, doi:10.1029/ 96JD03748.

Schröder, F., B. Kärcher, C. Duroure, J. Ström, A. Petzold, J.-F. Gayet, B. Strauss, P. Wendling, and S. Borrmann (2000a), On the transition of contrails into cirrus clouds, J. Atmos. Sci., 57, 464-480, doi:10.1175/ 1520-0469(2000)057<0464:OTTOCI $>2.0$. CO;2.

Schröder, F., C. A. Brock, R. Baumann, A. Petzold, R. Busen, P. Schulte, and M. Fiebig (2000b), In situ studies on volatile jet exhaust particle emissions: Impact of fuel sulfur content and environmental conditions on nuclei mode aerosols, J. Geophys. Res., 105, 19,941-19,954, doi:10.1029/2000JD900112.

Schumann, U. (1994), On the effect of emissions from aircraft engines on the state of the atmosphere, Ann. Geophys., 12, 365-384, doi:10.1007/ s00585-994-0365-0.

Schumann, U. (2000), Influence of propulsion efficiency on contrail formation, Aerosp. Sci. Technol., 4, 391-402, doi:10.1016/S12709638(00)01062-2.

Schumann, U. (2002), Contrail cirrus, in Cirrus, edited by D. K. Lynch et al., pp. 231-255, Oxford Univ. Press, New York.

Schumann, U. (2005), Formation, properties and climate effects of contrails, C. R. Phys., 6, 549-565, doi:10.1016/j.crhy.2005.05.002.

Schumann, U., H. Schlager, F. Arnold, R. Baumann, P. Haschberger, and O. Klemm (1998), Dilution of aircraft exhaust plumes at cruise altitudes, Atmos. Environ., 32, 3097-3103, doi:10.1016/S1352-2310(97)00455-X. 
Schumann, U., F. Arnold, R. Busen, J. Curtius, B. Kärcher, A. Kiendler, A. Petzold, H. Schlager, F. Schröder, and K.-H. Wohlfrom (2002), Influence of fuel sulfur on the composition of aircraft exhaust plumes: The experiments SULFUR 1-7, J. Geophys. Res., 107(D15), 4247, doi:10.1029/2001JD000813.

Shcherbakov, V., J.-F. Gayet, O. Jourdan, A. Minikin, J. Ström, and A. Petzold (2005), Assessment of cirrus cloud optical and microphysical data reliability by applying statistical procedures, J. Atmos. Oceanic Technol., 22, 409-420, doi:10.1175/JTECH1710.1.

Ström, J., and S. Ohlsson (1998), In situ measurements of enhanced crystal number densities in cirrus clouds caused by aircraft exhaust, J. Geophys. Res., 103, 11,355-11,361, doi:10.1029/98JD00807.

Stubenrauch, C. J., and U. Schumann (2005), Impact of air traffic on cirrus coverage, Geophys. Res. Lett., 32, L14813, doi:10.1029/2005GL022707.
Ziereis, H., H. Schlager, P. Schulte, P. F. J. van Velthoven, and F. Slemr (2000), Distributions of $\mathrm{NO}, \mathrm{NO}_{\mathrm{x}}$, and $\mathrm{NO}_{\mathrm{y}}$ in the upper troposphere and lower stratosphere between $28^{\circ}$ and $61^{\circ} \mathrm{N}$ during POLINAT 2 , J. Geophys. Res., 105, 3653-3664, doi:10.1029/1999JD900870.

R. Busen, B. Kärcher, A. Minikin, H. Schlager, and U. Schumann, Institut für Physik der Atmosphäre, Deutsches Zentrum für Luft- und Raumfahrt, Oberpfaffenhofen, Wessling, D-82234, Germany.

G. Febvre, J.-F. Gayet, O. Jourdan, and V. Shcherbakov, Laboratoire de Météorologie Physique, UMR6016, Université Blaise Pascal, CNRS, Aubière, F-63177, France. (febvre@opgc.univ-bpclermont.fr)

M. Fiebig, Norwegian Institute for Air Research, P.O. Box 100, Kjeller, N-2027, Norway. 